\title{
A Fourth-Order Boundary Value Problem with One-Sided Nagumo Condition
}

\author{
Wenjing Song ${ }^{1,2}$ and Wenjie Gao ${ }^{1}$ \\ ${ }^{1}$ Institute of Mathematics, Jilin University, Changchun 130012, China \\ ${ }^{2}$ Institute of Applied Mathematics, Jilin University of Finance and Economics, Changchun 130017, China \\ Correspondence should be addressed to Wenjing Song, songwenjing1978@sina.com
}

Received 10 January 2011; Accepted 9 March 2011

Academic Editor: I. T. Kiguradze

Copyright (c) 2011 W. Song and W. Gao. This is an open access article distributed under the Creative Commons Attribution License, which permits unrestricted use, distribution, and reproduction in any medium, provided the original work is properly cited.

The aim of this paper is to study a fourth-order separated boundary value problem with the righthand side function satisfying one-sided Nagumo-type condition. By making a series of a priori estimates and applying lower and upper functions techniques and Leray-Schauder degree theory, the authors obtain the existence and location result of solutions to the problem.

\section{Introduction}

In this paper we apply the lower and upper functions method to study the fourth-order nonlinear equation

$$
u^{(4)}(t)=f\left(t, u(t), u^{\prime}(t), u^{\prime \prime}(t), u^{\prime \prime \prime}(t)\right), \quad 0<t<1,
$$

with $f:[0,1] \times \mathbb{R}^{4} \rightarrow \mathbb{R}$ being a continuous function.

This equation can be used to model the deformations of an elastic beam, and the type of boundary conditions considered depends on how the beam is supported at the two endpoints $[1,2]$. We consider the separated boundary conditions

$$
\begin{gathered}
u(0)=u(1)=0, \\
a u^{\prime \prime}(0)-b u^{\prime \prime \prime}(0)=A, \\
c u^{\prime \prime}(1)+d u^{\prime \prime \prime}(1)=B
\end{gathered}
$$

with $a, b, c, d \in \mathbb{R}^{+}=(0,+\infty), A, B \in \mathbb{R}$. 
For the fourth-order differential equation

$$
\begin{gathered}
u^{(4)}(t)=f\left(t, u(t), u^{\prime}(t), u^{\prime \prime}(t), u^{\prime \prime \prime}(t)\right), \quad 0<t<1, \\
u(0)=u(1)=u^{\prime \prime}(0)=u^{\prime \prime}(1)
\end{gathered}
$$

the authors in [3] obtained the existence of solutions with the assumption that $f$ satisfies the two-sided Nagumo-type conditions. For more related works, interested readers may refer to [1-14]. The one-sided Nagumo-type condition brings some difficulties in studying this kind of problem, as it can be seen in [15-18].

Motivated by the above works, we consider the existence of solutions when $f$ satisfies one-sided Nagumo-type conditions. This is a generalization of the above cases. We apply lower and upper functions technique and topological degree method to prove the existence of solutions by making a priori estimates for the third derivative of all solutions of problems (1.1) and (1.2). The estimates are essential for proving the existence of solutions.

The outline of this paper is as follows. In Section 2, we give the definition of lower and upper functions to problems (1.1) and (1.2) and obtain some a priori estimates. Section 3 will be devoted to the study of the existence of solutions. In Section 4, we give an example to illustrate the conclusions.

\section{Definitions and A Priori Estimates}

Upper and lower functions will be an important tool to obtain a priori bounds on $u, u^{\prime}$, and $u^{\prime \prime}$. For this problem we define them as follows.

Definition 2.1. The functions $\alpha, \beta \in C^{4}(0,1) \cap C^{3}[0,1]$ verifying

$$
\alpha^{\prime \prime}(t) \leq \beta^{\prime \prime}(t), \quad \forall t \in[0,1]
$$

define a pair of lower and upper functions of problems (1.1) and (1.2) if the following conditions are satisfied:

(i) $\alpha^{(4)}(t) \geq f\left(t, \alpha(t), \alpha^{\prime}(t), \alpha^{\prime \prime}(t), \alpha^{\prime \prime \prime}(t)\right), \beta^{(4)}(t) \leq f\left(t, \beta(t), \beta^{\prime}(t), \beta^{\prime \prime}(t), \beta^{\prime \prime \prime}(t)\right)$,

(ii) $\alpha(0) \leq 0, \alpha(1) \leq 0, a \alpha^{\prime \prime}(0)-b \alpha^{\prime \prime \prime}(0) \leq A, c \alpha^{\prime \prime}(1)+d \alpha^{\prime \prime \prime}(1) \leq B, \beta(0) \geq 0, \beta(1) \geq$ $0, a \beta^{\prime \prime}(0)-b \beta^{\prime \prime \prime}(0) \geq A, c \beta^{\prime \prime}(1)+d \beta^{\prime \prime \prime}(1) \geq B$,

(iii) $\alpha^{\prime}(0)-\beta^{\prime}(0) \leq \min \{\beta(0)-\beta(1), \alpha(1)-\alpha(0), 0\}$.

Remark 2.2. By integration, from (iii) and (2.1), we obtain

$$
\alpha(t) \leq \beta(t), \quad \alpha^{\prime}(t) \leq \beta^{\prime}(t), \quad \forall t \in[0,1],
$$

that is, lower and upper functions, and their first derivatives are also well ordered.

To have an a priori estimate on $u^{\prime \prime \prime}$, we need a one-sided Nagumo-type growth condition, which is defined as follows. 
Definition 2.3. Given a set $E \subset[0,1] \times \mathbb{R}^{4}$, a continuous $f: E \rightarrow \mathbb{R}$ is said to satisfy the one-sided Nagumo-type condition in $E$ if there exists a real continuous function $h_{E}: \mathbb{R}_{0}^{+} \rightarrow$ $[k,+\infty)$, for some $k>0$, such that

$$
f\left(t, x_{0}, x_{1}, x_{2}, x_{3}\right) \leq h_{E}\left(\left|x_{3}\right|\right), \quad \forall\left(t, x_{0}, x_{1}, x_{2}, x_{3}\right) \in E,
$$

with

$$
\int_{0}^{+\infty} \frac{s}{h_{E}(s)} d s=+\infty
$$

Lemma 2.4. Let $\Gamma_{i}(t), \gamma_{i}(t) \in C([0,1], \mathbb{R})$ satisfy

$$
\Gamma_{i}(t) \geq \gamma_{i}(t), \quad \forall t \in[0,1], i=0,1,2,
$$

and consider the set

$$
E=\left\{\left(t, x_{0}, x_{1}, x_{2}, x_{3}\right) \in[0,1] \times \mathbb{R}^{4}: \gamma_{i}(t) \leq x_{i} \leq \Gamma_{i}(t), i=0,1,2\right\} .
$$

Let $f:[0,1] \times \mathbb{R}^{4} \rightarrow \mathbb{R}$ be a continuous function satisfying one-sided Nagumo-type condition in $E$.

Then, for every $\rho>0$, there exists an $R>0$ such that for every solution $u(t)$ of problems (1.1) and (1.2) with

$$
\begin{gathered}
u^{\prime \prime \prime}(0) \leq \rho, \quad u^{\prime \prime \prime}(1) \geq-\rho, \\
\gamma_{i}(t) \leq u^{(i)}(t) \leq \Gamma_{i}(t),
\end{gathered}
$$

for $i=0,1,2$ and every $t \in[0,1]$, one has $\left\|u^{\prime \prime \prime}\right\|_{\infty}<R$.

Proof. Let $u$ be a solution of problems (1.1) and (1.2) such that (2.7) and (2.8) hold. Define

$$
\eta:=\max \left\{\Gamma_{2}(1)-\gamma_{2}(0), \Gamma_{2}(0)-\gamma_{2}(1)\right\} \text {. }
$$

Assume that $\rho \geq \eta$, and suppose, for contradiction, that $\left|u^{\prime \prime \prime}(t)\right|>\rho$ for every $t \in(0,1)$. If $u^{\prime \prime \prime}(t)>\rho$ for every $t \in(0,1)$, then we obtain the following contradiction:

$$
\Gamma_{2}(1)-\gamma_{2}(0) \geq u^{\prime \prime}(1)-u^{\prime \prime}(0)=\int_{0}^{1} u^{\prime \prime \prime}(t) d t>\int_{0}^{1} \rho d t \geq \Gamma_{2}(1)-\gamma_{2}(0) .
$$

If $u^{\prime \prime \prime}(t)<-\rho$ for every $t \in(0,1)$, a similar contradiction can be derived. So there is a $\tilde{t} \in(0,1)$ such that $\left|u^{\prime \prime \prime}(\widetilde{t})\right| \leq \rho$. By (2.4) we can take $R_{1}>\rho$ such that

$$
\int_{\rho}^{R_{1}} \frac{s}{h_{E}(s)} d s>\max _{t \in[0,1]} \Gamma_{2}(t)-\min _{t \in[0,1]} \gamma_{2}(t)
$$


If $\left|u^{\prime \prime \prime}(t)\right| \leq \rho$ for every $t \in[0,1]$, then we have trivially $\left|u^{\prime \prime \prime}(t)\right|<R_{1}$. If not, then we can take $t_{1} \in[0,1)$ such that $u^{\prime \prime \prime}\left(t_{1}\right)<-\rho$ or $t_{1} \in(0,1]$ such that $u^{\prime \prime \prime}\left(t_{1}\right)>\rho$. Suppose that the first case holds. By (2.7) we can consider $t_{1}<t_{0} \leq 1$ such that

$$
u^{\prime \prime \prime}\left(t_{0}\right)=-\rho, \quad u^{\prime \prime \prime}(t)<-\rho, \quad \forall t \in\left[t_{1}, t_{0}\right) .
$$

Applying a convenient change of variable, we have, by (2.3) and (2.11),

$$
\begin{aligned}
\int_{-u^{\prime \prime}\left(t_{0}\right)}^{-u^{\prime \prime \prime}\left(t_{1}\right)} \frac{s}{h_{E}(s)} d s & =\int_{t_{0}}^{t_{1}} \frac{-u^{\prime \prime \prime}(t)}{h_{E}\left(-u^{\prime \prime \prime}(t)\right)}\left(-u^{(4)}(t)\right) d t \\
& =\int_{t_{1}}^{t_{0}} \frac{-u^{\prime \prime \prime}(t)}{h_{E}\left(-u^{\prime \prime \prime}(t)\right)} f\left(t, u(t), u^{\prime}(t), u^{\prime \prime}(t), u^{\prime \prime \prime}(t)\right) d t \\
& \leq \int_{t_{1}}^{t_{0}}-u^{\prime \prime \prime}(t) d t=u^{\prime \prime}\left(t_{1}\right)-u^{\prime \prime}\left(t_{0}\right) \\
& \leq \max _{t \in[0,1]} \Gamma_{2}(t)-\min _{t \in[0,1]} \gamma_{2}(t)<\int_{\rho}^{R_{1}} \frac{s}{h_{E}(s)} d s .
\end{aligned}
$$

Hence, $u^{\prime \prime \prime}\left(t_{1}\right)>-R_{1}$. Since $t_{1}$ can be taken arbitrarily as long as $u^{\prime \prime \prime}\left(t_{1}\right)<-\rho$, we conclude that $u^{\prime \prime \prime}(t)>-R_{1}$ for every $t \in[0,1)$ provided that $u^{\prime \prime \prime}(t)<-\rho$. Therefore,

In a similar way, it can be proved that $u^{\prime \prime \prime}(t)<R_{1}$, for every $t \in(0,1]$ if $u^{\prime \prime \prime}(t)>\rho$.

$$
\left|u^{\prime \prime \prime}(t)\right|<R_{1}, \quad \forall t \in[0,1]
$$

Consider now the case $\eta>\rho$, and take $R_{2}>\eta$ such that

$$
\int_{\eta}^{R_{2}} \frac{s}{h_{E}(s)} d s>\max _{t \in[0,1]} \Gamma_{2}(t)-\min _{t \in[0,1]} \gamma_{2}(t) .
$$

In a similar way, we may show that

$$
\left|u^{\prime \prime \prime}(t)\right|<R_{2}, \quad \forall t \in[0,1]
$$

Taking $R=\max \left\{R_{1}, R_{2}\right\}$, we have $\left\|u^{\prime \prime \prime}\right\|_{\infty}<R$.

Remark 2.5. Observe that the estimation $R$ depends only on the functions $h_{E}, \gamma_{2}, \Gamma_{2}$, and $\rho$ and it does not depend on the boundary conditions.

\section{Existence and Location Result}

In the presence of an ordered pair of lower and upper functions, the existence and location results for problems (1.1) and (1.2) can be obtained. 
Theorem 3.1. Suppose that there exist lower and upper functions $\alpha(t)$ and $\beta(t)$ of problems (1.1) and (1.2), respectively. Let $f:[0,1] \times \mathbb{R}^{4} \rightarrow \mathbb{R}$ be a continuous function satisfying the one-sided Nagumo-type conditions (2.3) and (2.4) in

$$
E_{*}=\left\{\left(t, x_{0}, x_{1}, x_{2}, x_{3}\right) \in[0,1] \times \mathbb{R}^{4}: \alpha(t) \leq x_{0} \leq \beta(t), \alpha^{\prime}(t) \leq x_{1} \leq \beta^{\prime}(t), \alpha^{\prime \prime}(t) \leq x_{2} \leq \beta^{\prime \prime}(t)\right\}
$$

If $f$ verifies

$$
f\left(t, \alpha(t), \alpha^{\prime}(t), x_{2}, x_{3}\right) \geq f\left(t, x_{0}, x_{1}, x_{2}, x_{3}\right) \geq f\left(t, \beta(t), \beta^{\prime}(t), x_{2}, x_{3}\right)
$$

for $\left(t, x_{2}, x_{3}\right) \in[0,1] \times \mathbb{R}^{2}$ and

$$
\left(\alpha(t), \alpha^{\prime}(t)\right) \leq\left(x_{0}, x_{1}\right) \leq\left(\beta(t), \beta^{\prime}(t)\right)
$$

where $\left(x_{0}, x_{1}\right) \leq\left(y_{0}, y_{1}\right)$ means $x_{0} \leq y_{0}$ and $x_{1} \leq y_{1}$, then problems (1.1) and (1.2) has at least one solution $u(t) \in C^{4}[0,1]$ satisfying

$$
\alpha(t) \leq u(t) \leq \beta(t), \quad \alpha^{\prime}(t) \leq u^{\prime}(t) \leq \beta^{\prime}(t), \quad \alpha^{\prime \prime}(t) \leq u^{\prime \prime}(t) \leq \beta^{\prime \prime}(t)
$$

for $t \in[0,1]$.

Proof. Define the auxiliary functions

$$
\delta_{i}\left(t, x_{i}\right)= \begin{cases}\alpha^{(i)}(t), & x_{i}<\alpha^{(i)}(t) \\ x_{i}, & \alpha^{(i)}(t) \leq x_{i} \leq \beta^{(i)}(t), \quad i=0,1,2 \\ \beta^{(i)}(t), & x_{i}>\beta^{(i)}(t)\end{cases}
$$

For $\lambda \in[0,1]$, consider the homotopic equation

$$
u^{(4)}(t)=\lambda f\left(t, \delta_{0}(t, u(t)), \delta_{1}\left(t, u^{\prime}(t)\right), \delta_{2}\left(t, u^{\prime \prime}(t)\right), u^{\prime \prime \prime}(t)\right)+u^{\prime \prime}(t)-\lambda \delta_{2}\left(t, u^{\prime \prime}(t)\right)
$$

with the boundary conditions

$$
\begin{gathered}
u(0)=u(1)=0, \\
u^{\prime \prime \prime}(0)=\frac{\lambda}{b}\left[a u^{\prime \prime}(0)-A\right], \\
u^{\prime \prime \prime}(1)=\frac{\lambda}{d}\left[B-c u^{\prime \prime}(1)\right] .
\end{gathered}
$$


Take $r_{1}>0$ large enough such that, for every $t \in[0,1]$,

$$
\begin{gathered}
-r_{1}<\alpha^{\prime \prime}(t) \leq \beta^{\prime \prime}(t)<r_{1}, \\
f\left(t, \alpha(t), \alpha^{\prime}(t), \alpha^{\prime \prime}(t), 0\right)-r_{1}-\alpha^{\prime \prime}(t)<0, \\
f\left(t, \beta(t), \beta^{\prime}(t), \beta^{\prime \prime}(t), 0\right)+r_{1}-\beta^{\prime \prime}(t)>0, \\
\frac{|A|}{a}<r_{1}, \quad \frac{|B|}{c}<r_{1} .
\end{gathered}
$$

Step 1. Every solution $u(t)$ of problems (3.6) and (3.7) satisfies

$$
\left|u^{(i)}(t)\right|<r_{1}, \quad \forall t \in[0,1]
$$

for $i=0,1,2$, for some $r_{1}$ independent of $\lambda \in[0,1]$.

Assume, for contradiction, that the above estimate does not hold for $i=2$. So there exist $\lambda \in[0,1], t \in[0,1]$, and a solution $u$ of (3.6) and (3.7) such that $\left|u^{\prime \prime}(t)\right| \geq r_{1}$. In the case $u^{\prime \prime}(t) \geq r_{1}$ define

$$
\max _{t \in[0,1]} u^{\prime \prime}(t):=u^{\prime \prime}\left(t_{0}\right) \geq r_{1}
$$

If $t_{0} \in(0,1)$, then $u^{\prime \prime \prime}\left(t_{0}\right)=0$ and $u^{(4)}\left(t_{0}\right) \leq 0$. Then, by (3.2) and (3.10), for $\lambda \in(0,1]$, the following contradiction is obtained:

$$
\begin{aligned}
0 \geq u^{(4)}\left(t_{0}\right) & =\lambda f\left(t_{0}, \delta_{0}\left(t_{0}, u\left(t_{0}\right)\right), \delta_{1}\left(t_{0}, u^{\prime}\left(t_{0}\right)\right), \delta_{2}\left(t_{0}, u^{\prime \prime}\left(t_{0}\right)\right), u^{\prime \prime \prime}\left(t_{0}\right)\right)+u^{\prime \prime}\left(t_{0}\right)-\lambda \delta_{2}\left(t_{0}, u^{\prime \prime}\left(t_{0}\right)\right) \\
& =\lambda f\left(t_{0}, \delta_{0}\left(t_{0}, u\left(t_{0}\right)\right), \delta_{1}\left(t_{0}, u^{\prime}\left(t_{0}\right)\right), \beta^{\prime \prime}\left(t_{0}\right), 0\right)+u^{\prime \prime}\left(t_{0}\right)-\lambda \beta^{\prime \prime}\left(t_{0}\right) \\
& \geq \lambda f\left(t_{0}, \beta\left(t_{0}\right), \beta^{\prime}\left(t_{0}\right), \beta^{\prime \prime}\left(t_{0}\right), 0\right)+u^{\prime \prime}\left(t_{0}\right)-\lambda \beta^{\prime \prime}\left(t_{0}\right) \\
& =\lambda\left[f\left(t_{0}, \beta\left(t_{0}\right), \beta^{\prime}\left(t_{0}\right), \beta^{\prime \prime}\left(t_{0}\right), 0\right)+r_{1}-\beta^{\prime \prime}\left(t_{0}\right)\right]+u^{\prime \prime}\left(t_{0}\right)-\lambda r_{1}>0 .
\end{aligned}
$$

For $\lambda=0$,

$$
0 \geq u^{(4)}\left(t_{0}\right)=u^{\prime \prime}\left(t_{0}\right) \geq r_{1}>0
$$

If $t_{0}=0$, then

$$
\max _{t \in[0,1]} u^{\prime \prime}(t):=u^{\prime \prime}(0) \geq r_{1}>0
$$

and $u^{\prime \prime \prime}\left(0^{+}\right)=u^{\prime \prime \prime}(0) \leq 0$. If $\lambda=0$, then $u^{\prime \prime \prime}(0)=0$ and so $u^{(4)}(0) \leq 0$. Therefore, the above computations with $t_{0}$ replaced by 0 yield a contradiction. For $\lambda \in(0,1]$, by $(3.11)$, we get the 
following contradiction:

$$
0 \geq u^{\prime \prime \prime}(0)=\frac{\lambda}{b}\left[a u^{\prime \prime}(0)-A\right] \geq \frac{\lambda}{b}\left[a r_{1}-A\right]>0
$$

The case $t_{0}=1$ is analogous. Thus, $u^{\prime \prime}(t)<r_{1}$ for every $t \in[0,1]$. In a similar way, we may prove that $u^{\prime \prime}(t)>-r_{1}$ for every $t \in[0,1]$.

By the boundary condition (3.7) there exists a $\xi \in(0,1)$, such that $u^{\prime}(\xi)=0$. Then by integration we obtain

$$
\begin{gathered}
\left|u^{\prime}(t)\right|=\left|\int_{\xi}^{t} u^{\prime \prime}(s) d s\right|<r_{1}|t-\xi| \leq r_{1}, \\
|u(t)|=\left|\int_{0}^{t} u^{\prime}(s) d s\right|<r_{1} t \leq r_{1} .
\end{gathered}
$$

Step 2. There is an $R>0$ such that for every solution $u(t)$ of problems (3.6) and (3.7)

$$
\left|u^{\prime \prime \prime}(t)\right|<R, \quad \forall t \in[0,1]
$$

with $R$ independent of $\lambda \in[0,1]$.

Consider the set

$$
E_{r_{1}}=\left\{\left(t, x_{0}, x_{1}, x_{2}, x_{3}\right) \in[0,1] \times \mathbb{R}^{4}:-r_{1} \leq x_{i} \leq r_{1}, i=0,1,2\right\}
$$

and for $\lambda \in[0,1]$ the function $F_{\mathcal{\lambda}}: E_{r_{1}} \rightarrow \mathbb{R}$ given by

$$
F_{\lambda}\left(t, x_{0}, x_{1}, x_{2}, x_{3}\right)=\lambda f\left(t, \delta_{0}\left(t, x_{0}\right), \delta_{1}\left(t, x_{1}\right), \delta_{2}\left(t, x_{2}\right), x_{3}\right)+x_{2}-\lambda \delta_{2}\left(t, x_{2}\right)
$$

In the following we will prove that the function $F_{\lambda}$ satisfies the one-sided Nagumo-type conditions (2.3) and (2.4) in $E_{r_{1}}$ independently of $\lambda \in[0,1]$. Indeed, as $f$ verifies (2.3) in $E_{*}$, then

$$
\begin{aligned}
F_{\lambda}\left(t, x_{0}, x_{1}, x_{2}, x_{3}\right) & =\lambda f\left(t, \delta_{0}\left(t, x_{0}\right), \delta_{1}\left(t, x_{1}\right), \delta_{2}\left(t, x_{2}\right), x_{3}\right)+x_{2}-\lambda \delta_{2}\left(t, x_{2}\right) \\
& \leq h_{E_{*}}\left(\left|x_{3}\right|\right)+r_{1}-\lambda \alpha^{\prime \prime}(t) \leq h_{E_{*}}\left(\left|x_{3}\right|\right)+2 r_{1}
\end{aligned}
$$

So, defining $h_{E_{r_{1}}}(t)=h_{E_{*}}\left(\left|x_{3}\right|\right)+2 r_{1}$ in $\mathbb{R}_{0}^{+}$, we see that $F_{\mathcal{\lambda}}$ verifies (2.3) with $E$ and $h_{E}$ replaced by $E_{r_{1}}$ and $h_{E_{r_{1}}}$, respectively. The condition (2.4) is also verified since

$$
\int_{0}^{+\infty} \frac{s}{h_{E_{r_{1}}}(s)} d s=\int_{0}^{+\infty} \frac{s}{h_{E_{*}(s)+2 r_{1}}} d s \geq \frac{1}{1+2 r_{1} / k} \int_{0}^{+\infty} \frac{s}{h_{E_{*}(s)}} d s=+\infty
$$


Therefore, $F_{\lambda}$ satisfies the one-sided Nagumo-type condition in $E_{r_{1}}$ with $h_{E}$ replaced by $h_{E_{r_{1}}}$, with $r_{1}$ independent of $\lambda \in[0,1]$.

Moreover, for

$$
\rho:=\max \left\{\frac{a r_{1}+|A|}{b}, \frac{|B|+c r_{1}}{d}\right\}
$$

every solution $u$ of (3.6) and (3.7) satisfies

$$
\begin{gathered}
u^{\prime \prime \prime}(0)=\frac{\lambda}{b}\left[a u^{\prime \prime}(0)-A\right] \leq \frac{\lambda}{b}\left[a r_{1}+|A|\right] \leq \rho, \\
u^{\prime \prime \prime}(1)=\frac{\lambda}{d}\left[B-c u^{\prime \prime}(1)\right] \geq-\frac{\lambda}{d}\left[|B|+c r_{1}\right] \geq-\rho .
\end{gathered}
$$

Define

$$
\gamma_{i}(t):=-r_{1}, \quad \Gamma_{i}(t):=r_{1}, \quad \text { for } i=0,1,2
$$

The hypotheses of Lemma 2.4 are satisfied with $E$ replaced by $E_{r_{1}}$. So there exists an $R>0$, depending on $r_{1}$ and $h_{E_{r_{1}}}$, such that $\left|u^{\prime \prime \prime}(t)\right|<R$ for every $t \in[0,1]$. As $r_{1}$ and $h_{E_{r_{1}}}$ do not depend on $\lambda$, we see that $R$ is maybe independent of $\lambda$.

Step 3. For $\lambda=1$, the problems (3.6) and (3.7) has at least one solution $u_{1}(t)$.

Define the operators

$$
L: C^{4}([0,1]) \subset C^{3}([0,1]) \longrightarrow C([0,1]) \times \mathbb{R}^{4}
$$

by

$$
L u=\left(u^{(4)}-u^{\prime \prime}, u(0), u(1), u^{\prime \prime \prime}(0), u^{\prime \prime \prime}(1)\right)
$$

and for $\lambda \in[0,1], \mathcal{N}_{\curlywedge}: C^{3}([0,1]) \rightarrow C([0,1]) \times \mathbb{R}^{4}$ by

$$
\mathcal{N}_{\lambda} u=\left(\lambda f\left(t, \delta_{0}(t, u(t)), \delta_{1}\left(t, u^{\prime}(t)\right), \delta_{2}\left(t, u^{\prime \prime}(t)\right), u^{\prime \prime \prime}(t)\right)-\lambda \delta_{2}\left(t, u^{\prime \prime}(t)\right), 0,0, A_{\curlywedge}, B_{\curlywedge}\right),
$$

with

$$
\begin{aligned}
& A_{\curlywedge}:=\frac{\lambda}{b}\left[a u^{\prime \prime}(0)-A\right], \\
& B_{\curlywedge}:=\frac{\lambda}{d}\left[B-c u^{\prime \prime}(1)\right] .
\end{aligned}
$$


Observe that $L$ has a compact inverse. Therefore, we can consider the completely continuous operator

$$
T_{\lambda}:\left(C^{3}([0,1]), \mathbb{R}\right) \longrightarrow\left(C^{3}([0,1]), \mathbb{R}\right)
$$

given by

$$
T_{\lambda}(u)=L^{-1} \mathcal{N}_{\curlywedge}(u)
$$

For $R$ given by Step 2, take the set

$$
\Omega=\left\{x \in C^{3}([0,1]):\left\|x^{(i)}\right\|_{\infty}<r_{1}, i=0,1,2,\left\|x^{\prime \prime \prime}\right\|_{\infty}<R\right\} .
$$

By Steps 1 and 2 , degree $d\left(I-T_{\lambda}, \Omega, 0\right)$ is well defined for every $\lambda \in[0,1]$ and by the invariance with respect to a homotopy

$$
d\left(I-T_{0}, \Omega, 0\right)=d\left(I-T_{1}, \Omega, 0\right)
$$

The equation $x=T_{0}(x)$ is equivalent to the problem

$$
\begin{gathered}
u^{(4)}(t)=u^{\prime \prime}(t), \\
u(0)=u(1)=u^{\prime \prime \prime}(0)=u^{\prime \prime \prime}(1)=0
\end{gathered}
$$

and has only the trivial solution. Then, by the degree theory,

$$
d\left(I-T_{0}, \Omega, 0\right)= \pm 1
$$

So the equation $T_{1}(x)=x$ has at least one solution, and therefore the equivalent problem

$$
\begin{gathered}
u^{(4)}(t)=f\left(t, \delta_{0}(t, u(t)), \delta_{1}\left(t, u^{\prime}(t)\right), \delta_{2}\left(t, u^{\prime \prime}(t)\right), u^{\prime \prime \prime}(t)\right)+u^{\prime \prime}(t)-\delta_{2}\left(t, u^{\prime \prime}(t)\right), \\
u(0)=u(1)=0, \\
a u^{\prime \prime}(0)-b u^{\prime \prime \prime}(0)=A, \\
c u^{\prime \prime}(1)+d u^{\prime \prime \prime}(1)=B
\end{gathered}
$$

has at least one solution $u_{1}(t)$ in $\Omega$.

Step 4. The function $u_{1}(\mathrm{t})$ is a solution of the problems (1.1) and (1.2). 
The proof will be finished if the above function $u_{1}(t)$ satisfies the inequalities

$$
\alpha(t) \leq u_{1}(t) \leq \beta(t), \quad \alpha^{\prime}(t) \leq u_{1}^{\prime}(t) \leq \beta^{\prime}(t), \quad \alpha^{\prime \prime}(t) \leq u_{1}^{\prime \prime}(t) \leq \beta^{\prime \prime}(t) .
$$

Assume, for contradiction, that there is a $\bar{t} \in[0,1]$ such that $u_{1}^{\prime \prime}(\bar{t})>\beta^{\prime \prime}(\bar{t})$, and define

$$
\max _{t \in[0,1]}\left[u_{1}^{\prime \prime}(t)-\beta^{\prime \prime}(t)\right]:=u_{1}^{\prime \prime}\left(t_{2}\right)-\beta^{\prime \prime}\left(t_{2}\right)>0
$$

If $t_{2} \in(0,1)$, then $u_{1}^{\prime \prime \prime}\left(t_{2}\right)=\beta^{\prime \prime \prime}\left(t_{2}\right)$ and $u_{1}^{(4)}\left(t_{2}\right) \leq \beta^{(4)}\left(t_{2}\right)$. Therefore, by (3.2) and Definition 2.1, we obtain the contradiction

$$
\begin{aligned}
u_{1}^{(4)}\left(t_{2}\right)= & f\left(t_{2}, \delta_{0}\left(t_{2}, u_{1}\left(t_{2}\right)\right), \delta_{1}\left(t_{2}, u_{1}^{\prime}\left(t_{2}\right)\right), \delta_{2}\left(t_{2}, u_{1}^{\prime \prime}\left(t_{2}\right)\right), u_{1}^{\prime \prime \prime}\left(t_{2}\right)\right) \\
& +u_{1}^{\prime \prime}\left(t_{2}\right)-\delta_{2}\left(t_{2}, u_{1}^{\prime \prime}\left(t_{2}\right)\right) \\
= & f\left(t_{2}, \delta_{0}\left(t_{2}, u_{1}\left(t_{2}\right)\right), \delta_{1}\left(t_{2}, u_{1}^{\prime}\left(t_{2}\right)\right), \beta^{\prime \prime}\left(t_{2}\right), \beta^{\prime \prime \prime}\left(t_{2}\right)\right)+u_{1}^{\prime \prime}\left(t_{2}\right)-\beta^{\prime \prime}\left(t_{2}\right) \\
\geq & f\left(t_{2}, \beta\left(t_{2}\right), \beta^{\prime}\left(t_{2}\right), \beta^{\prime \prime}\left(t_{2}\right), \beta^{\prime \prime \prime}\left(t_{2}\right)\right) \geq \beta^{(4)}\left(t_{2}\right) .
\end{aligned}
$$

If $t_{2}=0$, then we have

$$
\begin{gathered}
\max _{t \in[0,1]}\left[u_{1}^{\prime \prime}(t)-\beta^{\prime \prime}(t)\right]:=u_{1}^{\prime \prime}(0)-\beta^{\prime \prime}(0)>0, \\
u_{1}^{\prime \prime \prime}(0)-\beta^{\prime \prime \prime}(0)=u_{1}^{\prime \prime \prime}\left(0^{+}\right)-\beta^{\prime \prime \prime}\left(0^{+}\right) \leq 0 .
\end{gathered}
$$

By Definition 2.1 this yields a contradiction

$$
u_{1}^{\prime \prime \prime}(0)=\frac{1}{b}\left[a u_{1}^{\prime \prime}(0)-A\right]>\frac{1}{b}\left[a \beta^{\prime \prime}(0)-A\right] \geq \beta^{\prime \prime \prime}(0)
$$

Then $t_{2} \neq 0$ and, by similar arguments, we prove that $t_{2} \neq 1$. Thus,

$$
u_{1}^{\prime \prime}(t) \leq \beta^{\prime \prime}(t), \quad \forall t \in[0,1]
$$

Using an analogous technique, it can be deduced that $\alpha^{\prime \prime}(t) \leq u_{1}^{\prime \prime}(t)$ for every $t \in[0,1]$. So we have

$$
\alpha^{\prime \prime}(t) \leq u_{1}^{\prime \prime}(t) \leq \beta^{\prime \prime}(t)
$$

On the other hand, by (1.2),

$$
0=u_{1}(1)-u_{1}(0)=\int_{0}^{1} u_{1}^{\prime}(t) d t=\int_{0}^{1}\left(u_{1}^{\prime}(0)+\int_{0}^{t} u_{1}^{\prime \prime}(s) d s\right) d t=u_{1}^{\prime}(0)+\int_{0}^{1} \int_{0}^{t} u_{1}^{\prime \prime}(s) d s d t
$$


that is,

$$
u_{1}^{\prime}(0)=-\int_{0}^{1} \int_{0}^{t} u_{1}^{\prime \prime}(s) d s d t
$$

Applying the same technique, we have

$$
-\int_{0}^{1} \int_{0}^{t} \beta^{\prime \prime}(s) d s d t=-\int_{0}^{1} \beta^{\prime}(t) d t+\beta^{\prime}(0)=\beta(0)-\beta(1)+\beta^{\prime}(0)
$$

and then by Definition 2.1 (iii), (3.44) and (3.46), we obtain

$$
\begin{aligned}
\alpha^{\prime}(0) & \leq \beta^{\prime}(0)-\beta(1)+\beta(0) \\
& =-\int_{0}^{1} \int_{0}^{t} \beta^{\prime \prime}(s) d s d t \leq-\int_{0}^{1} \int_{0}^{t} u_{1}^{\prime \prime}(s) d s d t=u_{1}^{\prime}(0), \\
\beta^{\prime}(0) & \geq \alpha^{\prime}(0)-\alpha(1)+\alpha(0) \\
& =-\int_{0}^{1} \int_{0}^{t} \alpha^{\prime \prime}(s) d s d t \geq-\int_{0}^{1} \int_{0}^{t} u_{1}^{\prime \prime}(s) d s d t=u_{1}^{\prime}(0),
\end{aligned}
$$

that is,

$$
\alpha^{\prime}(0) \leq u_{1}^{\prime}(0) \leq \beta^{\prime}(0)
$$

Since, by (3.44), $\beta^{\prime}(t)-u_{1}^{\prime}(t)$ is nondecreasing, we have by (3.49)

$$
\beta^{\prime}(t)-u_{1}^{\prime}(t) \geq \beta^{\prime}(0)-u_{1}^{\prime}(0) \geq 0
$$

and, therefore, $\beta^{\prime}(t) \geq u_{1}^{\prime}(t)$ for every $t \in[0,1]$. By the monotonicity of $\beta(t)-u_{1}(t)$,

$$
\beta(t)-u_{1}(t) \geq \beta(0)-u_{1}(0)=\beta(0) \geq 0,
$$

and so $\beta(t) \geq u_{1}(t)$ for every $t \in[0,1]$.

The inequalities $u_{1}^{\prime}(t) \geq \alpha^{\prime}(t)$ and $u_{1}(t) \geq \alpha(t)$ for every $t \in[0,1]$ can be proved in the same way. Then $u_{1}(t)$ is a solution of problems (1.1) and (1.2).

\section{An Example}

The following example shows the applicability of Theorem 3.1 when $f$ satisfies only the onesided Nagumo-type condition. 
Example 4.1. Consider now the problem

$$
\begin{gathered}
u^{(4)}(t)=-[3+u(t)]\left[e^{u^{\prime}(t)}\right]\left[u^{\prime \prime}(t)-2\right]^{2}-\left[u^{\prime \prime \prime}(t)\right]^{4}, \\
u(0)=u(1)=0, \\
u^{\prime \prime}(0)-u^{\prime \prime \prime}(0)=A, \\
u^{\prime \prime}(1)+u^{\prime \prime \prime}(1)=B
\end{gathered}
$$

with $A, B \in \mathbb{R}$. The nonlinear function

$$
f\left(t, x_{0}, x_{1}, x_{2}, x_{3}\right)=-\left(3+x_{0}\right) e^{x_{1}}\left(x_{2}-2\right)^{2}-\left(x_{3}\right)^{4}
$$

is continuous in $[0,1] \times \mathbb{R}^{4}$. If $A, B \in[-2,2]$, then the functions $\alpha, \beta:[0,1] \rightarrow \mathbb{R}$ defined by

$$
\alpha(t)=-t^{2}-t, \quad \beta(t)=t^{2}+t
$$

are, respectively, lower and upper functions of (4.1) and (4.2). Moreover, define

$$
E=\left\{\left(t, x_{0}, x_{1}, x_{2}, x_{3}\right) \in[0,1] \times \mathbb{R}^{4}:-t^{2}-t \leq x_{0} \leq t^{2}+t,-2 t-1 \leq x_{1} \leq 2 t+1,-2 \leq x_{2} \leq 2\right\}
$$

Then $f$ satisfies condition (3.2) and the one-sided Nagumo-type condition with $h_{E}\left(\left|x_{3}\right|\right)=1$, in $E$.

Therefore, by Theorem 3.1, there is at least one solution $u(t)$ of Problem (4.1) and (4.2) such that, for every $t \in[0,1]$,

$$
-t^{2}-t \leq u(t) \leq t^{2}+t, \quad-2 t-1 \leq u^{\prime}(t) \leq 2 t+1, \quad-2 \leq u^{\prime \prime}(t) \leq 2 .
$$

Notice that the function

$$
f\left(t, x_{0}, x_{1}, x_{2}, x_{3}\right)=-\left(3+x_{0}\right) e^{x_{1}}\left(x_{2}-2\right)^{2}-\left(x_{3}\right)^{4}
$$

does not satisfy the two-sided Nagumo condition.

\section{Acknowledgments}

The authors would like to thank the referees for their valuable comments on and suggestions regarding the original manuscript. This work was supported by NSFC (10771085), by Key Lab of Symbolic Computation and Knowledge Engineering of Ministry of Education, and by the 985 Program of Jilin University. 


\section{References}

[1] C. P. Gupta, "Existence and uniqueness theorems for the bending of an elastic beam equation," Applicable Analysis, vol. 26, no. 4, pp. 289-304, 1988.

[2] C. P. Gupta, "Existence and uniqueness theorems for a fourth order boundary value problem of Sturm-Liouville type," Differential and Integral Equations, vol. 4, no. 2, pp. 397-410, 1991.

[3] F. Minhós, T. Gyulov, and A. I. Santos, "Existence and location result for a fourth order boundary value problem," Discrete and Continuous Dynamical Systems. Series A, supplement, pp. 662-671, 2005.

[4] A. Cabada, M. D. R. Grossinho, and F. Minhós, "On the solvability of some discontinuous third order nonlinear differential equations with two point boundary conditions," Journal of Mathematical Analysis and Applications, vol. 285, no. 1, pp. 174-190, 2003.

[5] A. Cabada and R. L. Pouso, "Extremal solutions of strongly nonlinear discontinuous second-order equations with nonlinear functional boundary conditions," Nonlinear Analysis: Theory, Methods $\mathcal{E}$ Applications, vol. 42, no. 8, pp. 1377-1396, 2000.

[6] A. Cabada and R. L. Pouso, "Existence results for the problem $\left(\phi\left(u^{\prime}\right)\right)^{\prime}=f\left(t, u, u^{\prime}\right)$ with nonlinear boundary conditions," Nonlinear Analysis: Theory, Methods \& Applications, vol. 35, no. 2, pp. 221-231, 1999.

[7] C. de Coster, "La méthode des sur et sous solutions dans l'étude de problèmes aux limites," Départment de Mathématique, Faculté des Sciences, Université Catholique de Louvain, Février 1994.

[8] C. de Coster and P. Habets, "Upper and lower solutions in the theory of ODE boundary value problems: classical and recent results," in Non-Linear Analysis and Boundary Value Problems for Ordinary Differential Equations (Udine), vol. 371 of CISM Courses and Lectures, pp. 1-78, Springer, Vienna, Austria, 1996.

[9] M. do Rosário Grossinho and F. M. Minhós, "Existence result for some third order separated boundary value problems," Nonlinear Analysis: Theory, Methods E Applications, vol. 47, no. 4, pp. 2407-2418, 2001.

[10] M. R. Grossinho and F. Minhós, "Upper and lower solutions for higher order boundary value problems," Nonlinear Studies, vol. 12, no. 2, pp. 165-176, 2005.

[11] M. R. Grossinho and F. Minhós, "Solvability of some higher order two-point boundary value problems," in Proceedings of International Conference on Differential Equations and Their Applications (Equadiff 10), pp. 183-189, Prague, Czechoslovak, August 2001, CD-ROM papers.

[12] I. T. Kiguradze and B. L. Shekhter, "Singular boundary value problems for second-order ordinary differential equations," Itogi Nauki Tekh., Ser. Sovrem. Probl. Mat., Novejshie Dostizh., vol. 30, pp. 105201, 1987 (Russian), English translation in Journal of Soviet Mathematics, vol. 43, no. 2, pp. 2340-2417, 1988.

[13] F. M. Minhós and A. I. Santos, "Existence and non-existence results for two-point boundary value problems of higher order," in Proceedings of International Conference on Differential Equations (Equadiff 2003), pp. 249-251, World Sci. Publ., Hackensack, NJ, USA, 2005.

[14] M. Nagumo, "Ueber die Differentialgleichung $y^{\prime \prime}=f\left(x, y, y^{\prime}\right)$, " Proceedings of the Physico-Mathematical Society of Japan, vol. 1937, no. 3, pp. 861-866, 19.

[15] A. Cabada, "An overview of the lower and upper solutions method with nonlinear boundary value conditions," Boundary Value Problems, vol. 2011, Article ID 893753, 18 pages, 2011.

[16] M. R. Grossinho, F. M. Minhós, and A. I. Santos, "A third order boundary value problem with onesided Nagumo condition," Nonlinear Analysis: Theory, Methods E Applications, vol. 63, no. 5-7, pp 247-256, 2005.

[17] M. R. Grossinho, F. M. Minhós, and A. I. Santos, "Existence result for a third-order ODE with nonlinear boundary conditions in presence of a sign-type Nagumo control," Journal of Mathematical Analysis and Applications, vol. 309, no. 1, pp. 271-283, 2005.

[18] M. R. Grossinho, F. M. Minhós, and A. I. Santos, "Solvability of some third-order boundary value problems with asymmetric unbounded nonlinearities," Nonlinear Analysis: Theory, Methods $\mathcal{E}$ Applications, vol. 62, no. 7, pp. 1235-1250, 2005. 